\title{
Research on the Relationship between Regional Culture and Street Furniture Design
}

\author{
Yu QIAN* \\ City College of WUST, Wuhan, China \\ qy0618@126.com \\ ${ }^{*}$ Corresponding author
}

Keywords: Regional Culture, Street Furniture, Design.

\begin{abstract}
This paper is to clarify the interaction between regional culture and street furniture and introduce cultural symbols to furniture design. First of all, this paper analyzed the status quo of street furniture and focused on the two problems in its design- being unsystematic and lacking regional cultural characteristics. Then, it identified the theoretical significance and practical application of this research. By analyzing the influence of regional culture upon the concept of street furniture design and the effect of street furniture on the inheritance and innovation of regional culture, this paper concluded the methods of street furniture innovation--decomposition, isomorphism and variation. The results of this paper can provide theoretical guidance for the realization of the national, artistic, creative and cultural value of street furniture.
\end{abstract}

\section{Introduction}

With the continuous evolution of social life, squares, parks, streets, and large indoor public places have become "living rooms" opened to all residents. The changes in modern architectural space have provided a new development field for furniture design - furniture used in public space.

Furniture used in public space (street furniture) refers to a series of facilities set in public space for people to live healthily, comfortably and efficiently.[1] From the macro perspective, it includes garbage bins, chairs, bus station shelters, traffic signs, billboards, lighting facilities, flower beds, banners and so on. From the micro perspective, it includes chaise lounges, chairs, benches, tables, shelves etc. in public places.

Regional culture is a cultural type that is typical in a particular region, which refers to the cultural characteristics of a region drained in the long-term development of economy and the geographical environment. The Book of Han recorded, "Hundred miles make life styles different; thousand miles make customs different", which best summarized the idea that each place has its own custom, tradition and regional cultural characteristics. [2]

Street furniture is not isolated but an important part of the "human-culture-environment" system. Each city has its own unique landscape and cultural structure because of the difference in regional geography. Therefore, besides fulfilling the basic functions, street furniture must also reflect the history and uniqueness of a region to guarantee the continuation of regional culture.

\section{Status Quo of Street Furniture}

Furniture is often needed in public places, like traffic convergence sites, population gathering sites, resting areas, etc., to offer convenience and to strengthen people's concerns for the environment. At present, there are some unsatisfactory aspects in street furniture design.

\section{Being Unsystematic}

Street furniture is an integral part of the environment, which requires that its design agree with its surroundings. However, it is still a new concept that street furniture must be integrated with the environment, so furniture design and the design of city landscapes are often separated. The major 
reason is that too much emphasis has been put on practicality, whereas its artistic and cultural value has been ignored. In some places, public facilities are often placed casually without considering whether it is in harmony with the environment.

For example, if the external design of public buildings, such as museums, art galleries and train stations, has strong historical and cultural contents, but their indoor furniture belongs to modern minimalist style, this striking contrast will ruin the overall beauty.

In addition to the style, the size, the shape, the layout and quantity of street furniture should also match the environment so that it serves as ornaments and a part of the landscapes.

\section{Lacking Regional Cultural Characteristics}

As the city's "business card", street furniture plays the role of displaying the cultural and regional characteristics. Today, with the globalization of economy and society, the regional characteristics in furniture design have been weakened and the historical essence of a region has been ignored. Now China's large and medium cities have begun to emphasize the design of street furniture, but few of them reflect regional culture.

Street furniture should be adapted to the users' cultural levels, aesthetic features and regional cultural characteristics. Together with the surrounding landscapes, it is to form an environment rich in cultural atmosphere and humanistic care. China is a multi-ethnic country and has a vast territory. The north and the south differ greatly in climate, customs, way of life, and living environment. Therefore, it is very important to highlight the cultural characteristics in furniture design. [3]

There are many successful foreign cases. In the Nordic design, Jacobsen, Finn Juhl and Kaare Klint, as the representatives of furniture designers, mix the unique Nordic humanistic spirit into furniture design, breaking a new and prosperous field of design supported by regional culture.

But problems still exist, such as the lack of humanistic care, unreasonable use of materials, lack of scientific layout, etc.

\section{Significance of the Study}

In the course of development, regional culture formed through the long history of human settlement has the utmost aesthetic value. The unique historical and cultural heritage is the soul of a city, thus becoming the characteristic which distinguish it from the others. A city that has a rich culture is attractive. Street furniture is the most direct and effective culture carrier. It plays the role of inheriting the cultural and regional characteristics, reflecting the cultural taste and aesthetic orientation of the city residents. [4]

Therefore, as an important part of the environment, street furniture is the link between the public space and the people in it. Besides beautifying the environment and increasing practicability, street furniture design should also reflect regional culture and agree with the constructions, the landscapes and residents' way of life, highlighting the uniqueness of the city.

Integrating regional cultural elements with street furniture design not only broadens the mentality of design but also is an effective means of introducing, inheriting and innovating regional culture, and thus has positive significance both theoretically and practically.

\section{Interaction between Regional Culture and Street Furniture}

The rise of regional culture is bound to put forward new requirements for street furniture, while street furniture, given more cultural contents, will also promote the development of regional culture.

\section{Influence of Regional Culture upon Street Furniture}

Subjective and objective factors affect street furniture. The former includes social ideology, national cultural tradition and so on. The latter includes materials, structure, craft, as well as the producing methods and so on. All these aspects reflect the influence of regional culture. 


\section{Design Concept}

Regional culture has a profound impact on people's minds and affects people's behaviors, aesthetic standards and value orientation. It will undoubtedly influence the concept of street furniture design. For example, in the eyes of the Chinese people, red is a festive and lively color. But in the eyes of westerners, it symbolizes violence and blood. Such cases exemplify the different design concepts among different regions.

\section{Choosing the Material}

The embodiment of regional culture has to be achieved by visual elements, such as decorative patterns, materials, etc. Visible symbols have the common spirit-- the common regional cultural characteristics. For example, in Chu culture, the image of Phoenix is a typical symbol and can be seen everywhere. When choosing materials, Chinese people like to use wood, while westerners often use stones. These different regional cultural symbols constitute the characteristics of street furniture.

\section{Expressing Symbolic Meanings}

As a result of globalization, international styles have exerted great influence on furniture designs. With the growth of awareness of local, regional and national characteristics, people have new requirements for the design standards of street furniture. It is not restricted to fulfill its functions, but also has to be different. Good street furniture must help people to understand the history and culture of the city. It can be said that under the influence of regional culture, street furniture has more and more rich symbolic meanings. [5]

\section{Form of Setup}

Every country has its own features; every city has its own style; every district has its own traits. When placing street furniture, regional culture has to be analyzed first, and then whether street furniture is to be placed in a public area, where to place it, the number and the setup can be decided. ${ }^{[6]}$

\section{Enriching the Style}

The common feature of regional culture can be called "the style". One style can be shown in a number of categories, such as architecture, interior and exterior decoration, landscapes, product design, etc. Some regional culture directly breeds the unique artistic style of furniture. Tea furniture derived from the Chinese tea culture is the most typical example. Tea culture has created the unique Chinese tea furniture. Therefore, regional culture has a direct impact on street furniture and helps to create different furniture styles.

\section{Influence of Street Furniture upon Regional Culture}

Mr. Yang Yao once said, "The artistic style of furniture displays one aspect of a nation and its culture and reflects its artistic interest." [7]

Street furniture offer convenience to the residents' life. At the same time, it reflects a city's, even a nation's, cultural characteristics, humanistic spirits, design level and aesthetic preference. As a component of the "human-culture-environment" system, street furniture, combined with the buildings, is the image of the city, reflecting its environment, character and temperament and plays the role of introducing, displaying and publicizing regional culture.

As one of the visual symbols of city landscapes, street furniture will arouse people's memory, thinking and evaluation of the city's history and play a positive role in the shaping of regional culture. Street furniture is placed in public areas and serves as ornaments. At the same time, through conveying its symbolic meanings, it creates a rich cultural atmosphere in the originally dreary and quiet space. When appreciating these works, people can understand the regional history and tradition, realize the profound meanings of regional culture, get the edification of arts and improve their cultural tastes. 


\section{Innovative Ideas for Designing Street Furniture}

The embodiment of regional culture in street furniture is realized by the application of cultural symbols. Regional cultural symbols are unique resources of the city. Each symbol consists of a number of elements, and each element has many variants. Therefore, how to use these symbols is a problem the designers need to solve.

\section{Decomposition}

By analyzing the abstract or specific symbols, designers can find inspirations from the specialties, historical relics, color of the city and regional culture etc. and extract the basic elements that can reflect the geographical and cultural characteristics. Through re-formation, the elements can be transformed and applied to furniture design. This method will enhance the internal continuity and integrity of the city environment. For example, in Tujia culture and Hmong culture, richly-patterned brocade (known as xilankapu) is one of the most renowned elements. It is simple but rich, realistic but abstract, and is imbued with a strong smack of everyday life. The designer can decompose the abstract patterns and get the typical elements and mix them into the design of hollowed-out works, such as street lamps, seats, etc. so as to emphasize the regional culture. [8]

\section{Isomorphism}

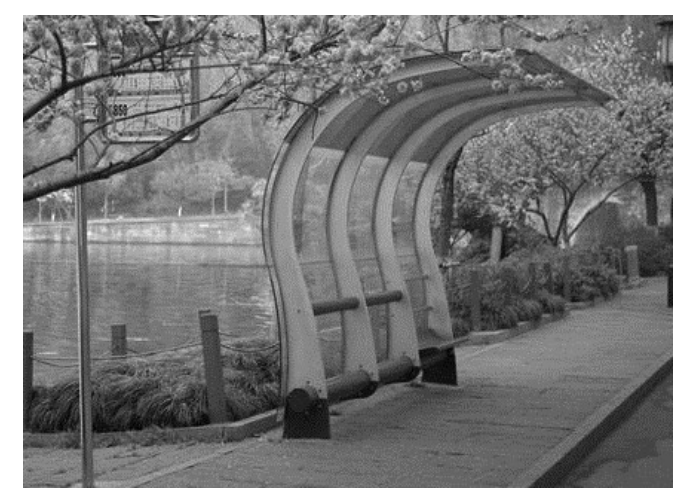

Fig. 1 A bus station nearby the West Lake

Isomorphism is one of the expressive methods in modern design. Designers can add cultural elements to the design of furniture and create a new shape but maintain the basic form of the prototype. For example, the representative image of the regional culture, such as architecture and auspicious patterns, can be placed in street furniture to create a new image. Isomorphism can give the regional cultural symbols a new image and make the street furniture agree with the environment. For example, the framework of the bus stations nearby the West Lake is made from organic glass and shaped into a curve, reflecting water culture of the lower reaches of the Yangze River.

\section{Variation}

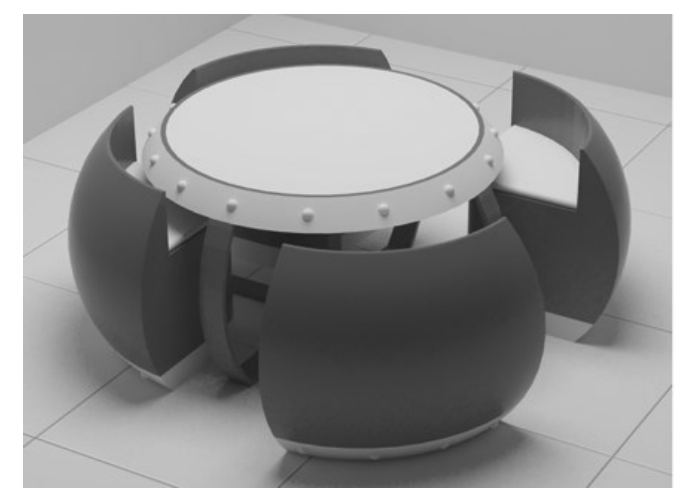

Fig. 2 Drum-shaped furniture 
This method is to extract the basic shape of cultural symbols, and then expand or modify it so as to integrate cultural elements with furniture. Expansion includes increasing and reducing the size, lengthening and shortening, and twisting etc. Modification is to change the morphological patterns, such as the shape, the color, the material and the texture. For example, figure 2 is a new image created by breaking the shape of a drum and moving the positions of its parts. This method helps to create novel and unique shapes, realizing the bold innovation of street furniture.

\section{Conclusion}

It may be said that the design of street furniture reflects the interaction among people, culture and environment. Different styles of street furniture constitute unique regional cultural symbols. Designers should explore the intrinsic nature of regional culture, meet the needs of modern aesthetic requirements and add new and modern elements to street furniture. At the same time, in furniture design, extracting cultural symbols that meet the aesthetic needs and exploring the combination of cultural contents and the external forms of furniture is helpful to realize the perfect integration of the meaning and the form, science and art, function and aesthetics in furniture design.

\section{Acknowledgement}

This paper is a current result for the 2017 Hubei province Humanities and Social Sciences project entitled "The Design of Street Furniture Based on the Regional Culture of Hubei Province" (project No.: 17G129).

\section{References}

[1] Shi-du BAO, Huai-liang WANG, Ming-hua SUN, City Furniture System Design, China Architecture \& Building Press, Beijing, 2006.

[2] Han YUE, The Relationship between Regional Culture and Furniture Design, China Metallurgical Education, 6 (2016) 76-78.

[3] Jing SUN, The Research on Street Furniture Design Scheme of Nanning City Based on Regional Cultural Background, Light Industry Science and Technology, 12 (2010)119-121.

[4] Cong-gong AN, Li-jun LI, The Symbiotic Relationship between City Furniture Design and Urban Pubic Space, Packaging Engineering, 33 (2012)133-135.

[5] Yong HUA, The Research of Street Furniture Design Based on the Regional Culture, Art Education, 7 (2011) 38-39.

[6] Xiao-meng LU, The Integration of Furniture and Urban-Discussing the Relation between Furniture Design and Urban Public Space, Art and Design, 5 (2009) 88-90.

[7] Jun-Hong HU, A Study on the Nationality of Chinese Furniture Design, Central South University of Forestry and Technology, 2007.

[8] He-peng XIE, Street Furniture Design under the Influence of Regional Cultural Symbols, Journal of Liming Vocational University, 1 (2009) 39-41. 